\title{
Child with Retinoblatoma: Diagnosis Announcement, Difficulties and Parent's Experiences
}

\author{
Aymen Kachouchi ${ }^{1, ~ *}$, Nabil Albab ${ }^{2}$, Mohammed Berghalout ${ }^{1}$, Sarah Belghmaidi ${ }^{2}$, Jihane Hakam ${ }^{2}$, \\ Imane Adali $^{1}$, Ibtissam Hajji ${ }^{2}$, Fatiha Manoudi ${ }^{1}$, Abdeljalil Moutaouakil ${ }^{2}$, Fatima Asri ${ }^{1}$ \\ ${ }^{1}$ Research Team for Mental Health, Department Of Psychiatry, Faculty of Medicine and Pharmacy, Caddi Ayyad University, Marrakech, \\ Morocco \\ ${ }^{2}$ Department of ophthalmology, Mohamed VI University Hospital of Marrakech, Marrakech, Morocco
}

Email address:

aymen.kach88@gmail.com (A. Kachouchi)

${ }^{*}$ Corresponding author

\section{To cite this article:}

Aymen Kachouchi, Nabil Albab, Mohammed Berghalout, Sarah Belghmaidi, Jihane Hakam, Imane Adali, Ibtissam Hajji, Fatiha Manoudi, Abdeljalil Moutaouakil, Fatima Asri. Child with Retinoblatoma: Diagnosis Announcement, Difficulties and Parent's Experiences. International Journal of Psychological and Brain Sciences. Vol. 4, No. 3, 2019, pp. 36-40. doi: 10.11648/j.ijpbs.20190403.12

Received: April 30, 2019; Accepted: June 10, 2019; Published: July 9, 2019

\begin{abstract}
Introduction: Retinoblastoma is a cancerous tumor of the retina. It is a rare pathology that affects each year, in France, one child out of 15,000 to 20,000 births. In Morocco, and in a prospective study conducted over 2 years and 3 months in the pediatric ophthalmology department in Casablanca, the annual incidence of retinoblastoma was estimated at 18 cases per year. The diagnosis of cancer, like any other serious illness, provokes an intense feeling of guilt in the child and in his parents. The retinoblastoma diagnosis announcement remains a difficult and delicate moment for caregivers and parents. The purpose of our work is to describe the experience of the parents of a child with retinoblastoma and to assess the degree of satisfaction of these children both for the treatment of their child and for clarity. information transmitted. Material and method: We conducted a descriptive cross-sectional study of the parents of children with retinoblastoma who received care in the ophthalmology department of Mohammed VI CHU Marrakech Morocco, and this over a period of one year from March 2016 to March 2017. The data is collected from parents with a questionnaire aimed to assess the parents' feelings and experiences around the following areas: the announcement structure, the climate of trust, proposal of formalizing personalized support. Results: The average age of children at the time of diagnosis is 11 months, with a male predominance, sex ratio is 1.4 . All families had one sick child. Retinoblastoma was bilateral in two cases. The surgical treatment was radical in all cases. $75 \%$ felt that the doctor was able to find the right words to announce the disease, and $42 \%$ felt he found the right words. At the time of diagnosis, 11 out of 12 families felt that they had received sufficient listening from the healthcare professionals and $75 \%$ felt that listening was quite sufficient. All parents report that the doctor who made the announcement spoke to them with care and respect and $92 \%$ spoke on the extreme positive score. $66 \%$ of families report receiving a personalized care plan. Conclusion: The results of this study will improve the overall care provided to children and integrate the difficulties expressed and felt by parents to the care project.
\end{abstract}

Keywords: Retinoblastoma, Parents, Cancer, Diagnosis Annoucement, Children

\section{Introduction}

Retinoblastoma is a cancerous tumor of the retina. It is a rare pathology that affects each year in France one child out of 15,000 to 20,000 births. It affects the eye, and the diagnosis is made most often before the age of five [1-3].

Conservative treatments are increasingly numerous: cryotherapy, brachytherapy by radioactive disks, thermochemotherapy (combination laser + chemotherapy), photocoagulation, more rarely radiotherapy and finally chemotherapy. In some cases when the tumor is very large and to prevent the cancer from spreading, the best therapeutic solution is enucleation [1-3].

In Morocco, and in a prospective study conducted over 2 years and 3 months in the pediatric ophthalmology 
department in Casablanca, the annual incidence of retinoblastoma was estimated at 18 cases per year [4]. The diagnosis of retinoblastoma, like any serious illness, provokes an intense feeling of guilt in both the child and his parents. The entire course of this disease is a painful and difficult test for a child and his family, because of the vital threat and cumbersome therapies.

The announcement of a serious illness is an important and delicate medical procedure, whose emotional impact on the patient can be considerable. This is a stressful time for doctors and parents $[5,6]$. Indeed, Razavi and Delvaux were able to demonstrate that the cumulative effect of stress due to communication problems with patients and their relatives leads to the exhaustion of professionals, causing tensions in the care relationship [7-8], these patients and their parents present with signs of post-traumatic stress that can be a barrier to access to appropriate care [9-10].

This is why the diagnosis announcement must be clear and be taken again according to the representations of the parents by specifying the real risks incurred by the child. It must also take into account the many reactions of family members. This remains difficult to achieve in the absence of a codified and evaluable announcement device, and a shortage of studies that are interested in the reactions and experiences of Moroccan parents in the face of this traumatic event.

It is in this context that our study aims to: describe the experience of the parents of a child with retinoblastoma and assess the degree of satisfaction of these children both for the therapeutic management of their child only for the clarity of the information transmitted.

\section{Materials and Method}

\subsection{Type of Study}

We conducted a descriptive cross-sectional study concerning the parents of children with retinoblastoma who had been treated in the ophthalmology department of the Mohammed VI Medical Center in Morocco, over a period of one year. from March 2016 to March 2017.

\subsection{Population}

Families were asked to participate in this study by telephone after 8 weeks of the consultation of the ad. If the parents agree to participate in the survey, the doctor suggests that they complete and sign the consent form. Twenty families were solicited, fifteen families accepted on the phone but only twelve signed the informed consent form.

The duration of 8 weeks was decided according to our professional experience in our service, necessary period for the parents to organize around this traumatic event, to have a global opinion on all the process of taking care, to have a sufficient distance members of the health care team to have an opinion free of constraints and challenges.

\subsection{Procedures}

An exploitation sheet to determine the socio-demographic characteristics of the sample, the characteristics of the pathology, the proposed treatment and the follow-up modalities. Then a questionnaire was proposed to parents that included 20 questions in Arabic dialect adapted from the questionnaire used in the study on the announcement of the diagnosis of cancer and the feeling of patients realized in 2011 by the French National Cancer Institute on the device accompaniment set up around the announcement and the feeling of sick people grouped according to the following areas [11]:

Structuring the announcement.

Establishment of a climate of trust.

Proposal and formalization of a personalized support.

The interviews took place in the ophthalmology department in the presence of the attending ophthalmologist and a psychiatrist. They were with one of the two parents depending on the availability and knowledge of the parent of the pathology history.

The collection of data was done in respect of anonymity and confidentiality of information.

\section{Results}

\subsection{Sociodemographic and Clinical Data}

The average age of children at the time of diagnosis is 11 months, with a male predominance, sex ratio is 1.4. All families had one sick child.

Retinoblastoma was bilateral in two cases. The surgical treatment was radical in all cases: Enucleation.

Only one child had divorced parents, $60 \%$ of the families had a low socio-economic level and did not have medical coverage.

As for parental education (Table 1), more than half of fathers and $2 / 3$ of mothers were illiterate.

Table 1. Parents' level of education.

\begin{tabular}{lll}
\hline Level of education & Father & Mother \\
\hline Illiterate & 7 & 9 \\
Primary & 2 & 2 \\
Secondary & 2 & 1 \\
High and university & 1 & 0 \\
\hline
\end{tabular}

No child had a family history of retinoblastoma.

At the time of diagnosis, the father was absent in $75 \%$ of cases.

The semi-structured interviews lasted an average of 60 minutes and were well accepted by the parents.

\subsection{Structuring the Announcement}

$75 \%$ felt that the doctor was able to find the right words to announce the disease, and $42 \%$ felt he found the right words.

$42 \%$ of families reported being offered access to caregiver support time. However, this support was done in an unstructured way either by a nurse or by an external doctor.

At the time of diagnosis, 11 out of 12 families felt that they had received adequate listening from the healthcare professionals and $75 \%$ felt that listening was quite sufficient. 
The vast majority of sick people (92\%) thought they had obtained answers to their questions and $16 \%$ to some of their questions.

In the doctor's interview for the therapeutic proposal, 9 out of 12 families (75\%) report having received information from the doctor about the effects of the treatment on the disease. This information was considered sufficient by $83 \%$ of families, with $67 \%$ ranking on the extreme positive score.

Although $58 \%$ of parents report that the doctor did not explicitly ask for their opinion on the treatment proposal, all parents felt they had time to talk to the doctor about the treatment.

More than half $(80 \%)$ of parents needed an average of 3 days to accept treatment.

\subsection{Establishment of a Climate of Trust}

All parents report that the doctor who made the announcement spoke to them with care and respect and $92 \%$ spoke on the extreme positive score.

Only $25 \%$ of families say they have found it difficult to join the team.

During caregiving time, $41 \%$ of sick families feel that they have received help and support.

\subsection{Proposal and Formalization of a Personalized Management}

$66 \%$ of families report receiving a personalized care plan.

More than half of the parents $(67 \%)$ felt that their social situation was not sufficiently taken into account, it was essentially families without basic medical coverage. All parents expressed a need for well-coded social support.

Nevertheless, $75 \%$ of parents expressed satisfaction with overall care and felt that the care provided corresponded to their expectations and needs.

Only one family has estimated that tumor recurrence is due to initial management.

The majority of the parents did not wish to have recourse to a psychiatrist after treatment, this decision was motivated essentially on the one hand by the presence of a sufficient family support and on the other hand by a lack of means.

\section{Discussion}

\subsection{Diagnostic Announcement}

In our study $75 \%$ of families feel that the doctor found the exact words to announce the diagnosis. In a similar study by Delage of 38 families of children with retinoblastoma described that all parents participating in his study were very satisfied with the medical information they receive, whether from ophthalmologists or pediatricians [12]. The interviews with the parents were marked by many stammerings, silences; with short answers: "uh", "finally", "good", "bah"...[12]. The parents at the time of the announcement consultation, and after days of waiting and confusion are faced with the psychic vagueness and the vagueness of the information. They are waiting for the information of the person who has the knowledge and who will ensure the care and the prognosis. They expect a concrete objective and empathic response. With retinoblastoma, it is the anxiety of death that is present: parents are afraid of losing their child, their reason for living, the extension of themselves after their disappearance [12-14]. Thus the words chosen to announce the diagnosis must be simple, the formulation must be unambiguous and must take into account the reactions of disbelief, psychic stupor, then revolt, despair on the part of the parents. Communication must be direct and nonviolent verbalization. It must be slow, leaving room for questions aimed at a request for reformulation by the patient. We must also take into consideration the singularity of each child and the peculiarities of each social milieu, the main element of criticism in our study. The moment of announcement can also define with the parents a certain number of contacts with the nursing staff, the associations of patients who can bring them help. This time of accompaniment should provide parents with sufficient listening, and allow them to rephrase some information given by the doctor and get answers to their questions about the disease [14-18].

\subsection{Emotional Aspects}

The announcement of a serious diagnosis is a traumatic event that upsets the psychic organization of the subject and the interactions with the environment.

At the time of the announcement, an atmosphere of worry and suffering is monopolizing all the attention of parents who are trying to find an explanation for this arbitrariness. Why our child? Against this feeling of arbitrariness arises an intense guilt as a defense mechanism, verbalized frequently and in many ways. Thus, the parents of the children think that they are not very vigilant in identifying the first symptoms of the disease or that they have tended to trivialize the symptoms. They feel guilty about not being too sick and not showing signs of a tumor. They may also be persuaded that the ordeal they endure is a deserved punishment for all kinds of shameful thoughts or misdeeds of which they have been guilty during their lifetime [14, 19].

After the announcement time different delayed reactions can have linker, the most common are: the amazement that follows the state of shock, verbalized by the mothers of our patients "Our life has turned upside down", "The time s 'stopped ". The denial, the family multiplies the consultations in search of other opinions with the hope that the diagnosis would be different. Depression as a defense reaction, it can result in a sad mood, increased sensitivity, loss of appetite and sleep. In our study, not all families had accepted the treatment initially proposed primarily by the father; $2 / 12$ families needed to take another view $[5,6,19]$.

Bennet and Bruce have shown that parents have symptoms of post-traumatic stress that remain present even after the end of treatment $[9,10]$. Norberg argued that moms are more at risk for higher stress levels than fathers, this is explained by the constant presence of the mother during all phases of management, which is consistent with our findings [20]. However, a study by Schepard that assessed the quality of 
life of 47 mothers of children with retinoblastoma did not show a significant difference from a control population [21].

Some authors focus on the notion of narcissistic injury. In fact, the sick child defeats the parental ideal and breaks the projects that the parents had formed for him. Parents narcissistically invest an extension of themselves as well as an ideal, that of the child capable of accomplishing what they themselves could not achieve. This ideal is unfeasible given the state of the child $[6,12,19,21]$.

Other studies are beginning to focus more and more on the emotions of caregivers who announce a difficult diagnosis, in our study we did not evaluate this important part of the diagnostic ad equation. Meier et al stress that these situations cause the doctor negative emotions, including stress, fear of not being empathic enough, doubts about his skills, feelings of guilt, or the anxiety of being sick to turn $[13,22]$. If the caregiver's state of anxiety exceeds a high level of intensity, it will certainly alter the care relationship in the short and long term, hence the need for support work [14, 23, 24].

This is supported by the investigation of Ptacek et al. [25], who found that the majority of physicians say that the stress experienced by the ad is not limited to the time of the announcement, but appears during the preparation phase and continues after the meeting with the patient.

\subsection{Recommendations}

Through this study, it seems essential to us to update the following recommendations: we must try as much as possible to personalize the appointments of surveillance and to take into consideration the social particularities of the families, to create a play area at the service to the day hospital and in the operating theater, improve the reception of these children in the other services (pediatrics, genetics, oncology...), encourage parents and the child to begin a psychological follow-up with a psychiatrist or a psychologist, establish a Well-codified and evaluable Retinoblastoma Announcement Device, facilitating multidisciplinarity by designating families a caregiver referent retinoblastoma in each service involved in the care, appoint a social worker to accompany the families of children in all the steps and to encourage the creation of parents' associations of children or former patients in order to share their experiences.

\section{Conclusion}

The act of informing is always complex all the more when it comes to announcing a serious diagnosis in a child. The announcement of a retinoblastoma is certainly a traumatic and painful event for the child and the parents. Thus, the task of the doctor in this situation proves difficult especially in the absence of a serious diagnostic announcement device, he is torn between his own affects of anxiety and anxiety and his duty to be empathetic and deliver a information taking into account the particularities of each family and providing specific support throughout the care.

\section{Declaration of Conflict of Interest}

The authors declare that they have no conflict of interest.

\section{References}

[1] Doz F, Brisse H, Stoppa-Lyonnet D. Retinoblastoma. Chapitre 16. In: Pinkerton CR, Plowman PN, Pieters R (eds). Paediatr Oncol 2004; 323-38.

[2] Doz F. Retinoblastoma: a review. Arch Pediatr 2006; 13: 1329-37.

[3] Livret d'information sur le rétinoblastome, version actualisée 2014 (www.retinostop.org).

[4] El Kettani A, Aderdour S, Daghouj G, Knari S, Zaghloul K, Zafad $\mathrm{S}$ et al. Rétinoblastome: Résultats préliminaires du protocole national de prise en charge au CHU de Casablanca. J fr ophtalmol 2014; 37 (2): 115-124.

[5] Ek U. Emotional reactions in parents and children after diagnosis and treatment of a malignant tumor in the eye. Child Care Health Dev 2000; 26 (5): 415-28.

[6] Delage M, Boisserolles V, Savignioni A, Desjardins L, Aerts I, Gauthier-Villars $M$ et al. Comment les parents perçoivent-ils la prise en charge de leur enfant atteint de rétinoblastome ? Rev Oncol Hematol Pediatr 2014; 2: 180-7.

[7] Razavi D, Delvaux N. Communication skills and psychological training in oncology. Eur J Cancer 1997; 33 (S6): S15-21.

[8] Delvaux N, Merckaert I, Marchal S, Libert Y, Conradt S, Boniver $\mathrm{J}$ et al. Physicians' communication with a cancer patient and a relative: A randomized study assessing the efficacy of consolidation workshops. Cancer 2005; 103 (11): 2397-411.

[9] Bruce M, Gumley D, Isham L, Fearon P, Phipps K. Posttraumatic stress symptoms in childhood brain tumour survivors and their parents. Child: Care, Health and Development 2011; 37 (2): 244-251.

[10] Bennett E, English MW, Rennoldson M, Starza-Smith A. Predicting parenting stress in caregivers of children with brain tumours. Psychooncology 2013; 22 (3): 629-636.

[11] Etude sur l'annonce du diagnostic de cancer et le ressenti des malades en 2011. INCa Mai 2012.

[12] Delage M, Alajane, F, Pacquement H, Seigneur E. Rétinoblastome de l'enfant: étude qualitative de l'expérience subjective des parents et de leur compréhension de la consultation d'oncogénétique à la recherche d'une prédisposition génétique. Psycho-Oncol 2015; 9: 160-64.

[13] Albarracin D, Jouffre S. L'annonce de mauvaises nouvelles: émotions et feed-back dans la formation des médecins. Psycho- Oncol 2014; 8: 177-82.

[14] Romano H. L'annonce d'un diagnostic grave. Rev med interne 2010; 31 (9): 626-30.

[15] Daydé MC. La relation d'aide en soins infirmiers, aspects réglementaires et conceptuels. Soins 2008; 53 (731): 35-8.

[16] Stadelmaier N, Lombard I, Duguey-Cachet O, Hugues J, Carton $\mathrm{O}$, Cosnefroy $\mathrm{O}$ et al. Le dispositif d'annonce en 
cancérologie: quel outil d'orientation vers la consultation psychologique? Psycho-Oncol 2009; 3: 176-183.

[17] Rannou S, Guirimand N, Cartran L, Tresvaux du Fraval F, Sahbatou Y, Lagrange JL et al. Le vécu de l'annonce d'un cancer à l'ère du dispositif d'annonce (2011). Psycho-Oncol 2011; 5: 227-234.

[18] Clément-Hryniewicz N, Paillaud E. Quand le mot cancer fait trauma Réflexions autour de l'annonce diagnostique de cancer. Psycho-Oncol 2008; 2: 44-48.

[19] Vrijmoet-Wiersma CM, van Klink JM, Kolk AM, Koopman HM, Ball LM, Maarten Egeler R. Assessment of parental psychological stress in pediatric cancer: A review. J Pediatr Psychol 2008; 33 (7): 694-706.

[20] Norberg AL et Green A. Stressors in the daily life of parents after a child's successful cancer treatment. J Psychosoc Oncol 200; 25 (3): 113-122.

[21] Sheppard L, Eiser C, Kingston J. Mothers' perceptions of children's quality of life following early diagnosis and treatment for retinoblastoma. Child Care Health Dev 2005; 31 : $137-42$.

[22] Meier DE, Back AL, Morrisson RS. The inner life of physicians and care of the Serious ill. JAMA 2001; 286 (23): 3007-14.

[23] Lecompte H. Informer sur les séquelles des cancers pédiatriques: difficultés du médecin et traitement de l'information par le patient. Psycho-Oncol 2009; 3: 217-221.

[24] Fraisse P. Le dispositif d'annonce en cancérologie: entre éthique et pratique. Rev mal respir 2007; 24 (5): 569-74.

[25] Ptacek JT, Fries EA, Eberhardt TL, Ptacek JJ. Breaking bad news to patients: physicians' perception of the process. Support Care Cancer 1999; 7 (3): 113-20. 